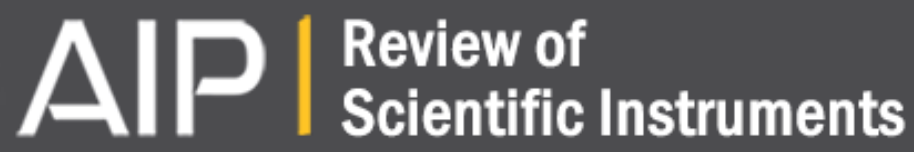

Preliminary characterization of a low-powered microwave induced flame plasma for direct organic solvent nebulization

Kin C. Ng and Phil Bucay

Citation: Review of Scientific Instruments 82, 125101 (2011); doi: 10.1063/1.3664618

View online: http://dx.doi.org/10.1063/1.3664618

View Table of Contents: http://scitation.aip.org/content/aip/journal/rsi/82/12?ver=pdfcov

Published by the AIP Publishing

\section{Articles you may be interested in}

Examination of ionic wind and cathode sheath effects in a E-field premixed flame with ion density measurements Phys. Plasmas 23, 043504 (2016); 10.1063/1.4945614

Stabilization of a lean premixed flame using non-thermal plasma

J. Appl. Phys. 115, 223304 (2014); 10.1063/1.4872471

Characterization of Hall effect thruster propellant distributors with flame visualization

Rev. Sci. Instrum. 84, 013302 (2013); 10.1063/1.4774049

Two-dimensional direct numerical simulation evaluation of the flame-surface density model for flames developing from an ignition kernel in lean methane/air mixtures under engine conditions

Phys. Fluids 24, 105108 (2012); 10.1063/1.4757655

Properties of plasma flames sustained by microwaves and burning hydrocarbon fuels

Phys. Plasmas 13, 113501 (2006); 10.1063/1.2363348

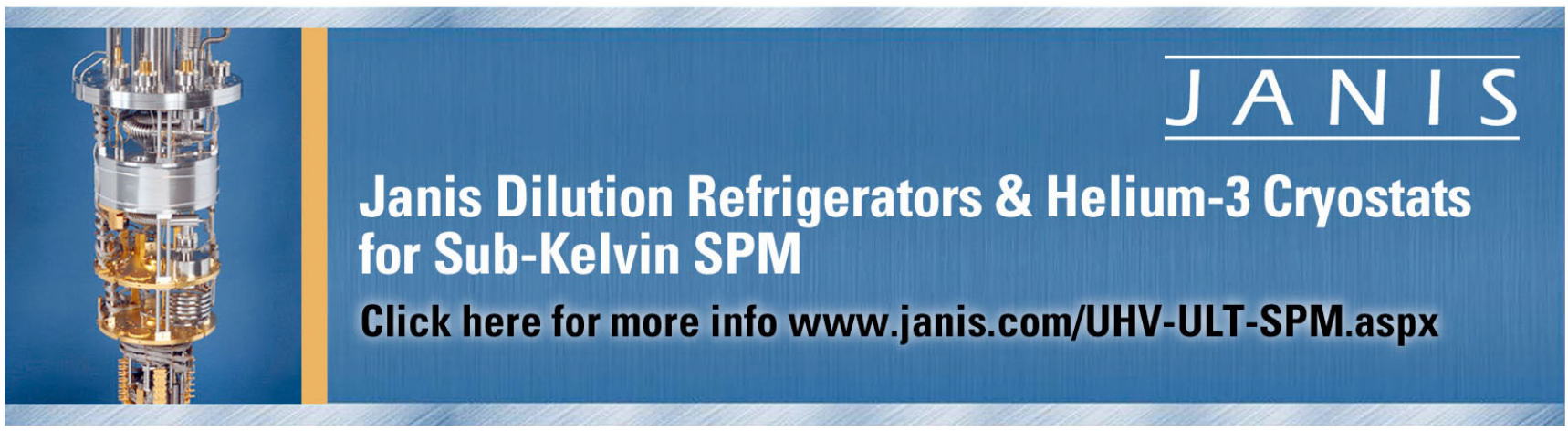




\title{
Preliminary characterization of a low-powered microwave induced flame plasma for direct organic solvent nebulization
}

\author{
Kin C. Nga) and Phil Bucay \\ Department of Chemistry, California State University, 2555 East San Ramon Ave., M/S SB70, Fresno, \\ California 93740-8034, USA
}

(Received 12 October 2011; accepted 6 November 2011; published online 1 December 2011)

\begin{abstract}
A low powered $(<90 \mathrm{~W})$ microwave-induced plasma has been generated at atmospheric pressure by using a Beenakker cavity, a laboratory constructed torch, and a gas mixture of argon (400 $\mathrm{ml} / \mathrm{min})$, hydrogen $(100 \mathrm{ml} / \mathrm{min})$, and air $(130 \mathrm{ml} / \mathrm{min})$. This plasma has an excitation temperature of 3300 $3500 \mathrm{~K}$, electron number density of $7 \times 10^{14} \mathrm{~cm}^{-3}$, and easily accepts direct methanol and ethanol introduction with a $1 \mathrm{ml} / \mathrm{min}$ solution nebulization rate. Detection limits $(3 \sigma)$ obtained from the atomic emission signals of $\mathrm{Li}, \mathrm{Sr}$, and $\mathrm{Cr}$ in water are 15, 120, and $290 \mathrm{ng} / \mathrm{ml}$, respectively. Similarly, detection limits for the metals in methanol are 15, 120, and $260 \mathrm{ng} / \mathrm{ml}$, respectively, and in ethanol they are 25,360 , and $330 \mathrm{ng} / \mathrm{ml}$, respectively. The linear dynamic range is greater than three orders of magnitude. () 2011 American Institute of Physics. [doi:10.1063/1.3664618]
\end{abstract}

\section{INTRODUCTION}

Plasmas are used extensively in atomic spectroscopy ${ }^{1,2}-$ as atom sources in absorption, emission, and fluorescence spectroscopy, and as ion sources in mass spectroscopy. Common analytical plasmas are the direct current plasma, the inductively coupled plasma, and the microwave induced plasma (MIP) — with the MIP operating at lowest power levels $(<100 \mathrm{~W})$ and gas-consumption rates $(<1 \mathrm{l} / \mathrm{min})$. These attractive MIP features also limit the MIP's capability and its use mainly as a detector in gas chromatography applications. ${ }^{3}$ Introduction of liquid into the low-powered MIP is challenging since the available power is insufficient for simultaneously performing de-solvation and excitation. The liquid feeding rate must be low enough for sustaining the plasma. A direct injection nebulizer has been coupled with a low powered argon-MIP (Ref. 4) and He-MIP. ${ }^{5}$ Direct nebulization of pure methanol and acetonitrile was successful with the argon-MIP, but the solution uptake rate must be less than $20 \mu \mathrm{L} / \mathrm{min}^{4}{ }^{4}$ The He-MIP was tolerant to $10 \%$ methanol solutions. ${ }^{5}$

It is desirable to have a low-power MIP capable of handling solutions of aqueous and non-aqueous solvents. In addition, the solution nebulization uptake rate should be $\sim 1 \mathrm{ml} / \mathrm{min}$. These capabilities will then make the MIP compatible for coupling as a detector with conventional highperformance liquid chromatograph, implementing the wealth of applications already developed in high-performance liquid chromatography (HPLC). The direct nebulization of aqueous solutions into a low-powered MIP has been achieved to a certain extent; ${ }^{6}$ however, the direct nebulization of organic solvents remains difficult. ${ }^{1,2}$ Some of the difficulties arrive from vapor-loading and insufficient power for maintaining the plasma state.

\footnotetext{
a) Author to whom correspondence should be addressed. Electronic mail: kinn@csufresno.edu.
}

We have employed a Beenakker $\mathrm{TM}_{010}$ cavity ${ }^{2,7}$ and a gas mixture of argon, hydrogen, and air, and achieved $\sim 1 \mathrm{ml} / \mathrm{min}$ solution nebulization rate with pure methanol and ethanol. This paper describes the development and analytical evaluations.

\section{EXPERIMENTAL}

\section{A. The pre-mix chamber and torch-base-adapter}

Hydrogen and air were pre-mixed in a laboratory built chamber, and directed into a laboratory-built torch-baseadapter. The design and construction of the chamber-torch assembly is shown in Fig. 1.

The mixing chamber (MC) and torch base was used to combine combustion and argon gases before entering the alumina discharge tube. The mixing chamber was made from a 2-in. tapered brass nipple that was bored on the bottom to accommodate the sample introduction tube $(0.0625$ in. outside diameter and $0.0312 \mathrm{in}$. inside diameter). The top of the MC was tapped and beveled to allow for leak proof seal attached to both of the MC ends to allow the gases to flow into the chamber. Approximately 6 in. before the $1 / 2$ in. compression fitting, 50 psi pressure release valves were installed in case of a sudden increase in pressure making certain safety would be maintained. The torch-base was machined from 1.5 in. brass rod stock and was threaded to a diameter of 9/16 in. to allow for the accommodation of the alumina discharge tube adapter. The bottom of the base was threaded and machined precisely for the insertion of the modified flame ionization detector mini torch. The mini brass torch was precision bored to ensure proper flow geometry and a diameter of $2 \mathrm{~mm}$ for accommodating the sample introduction tube. The alumina discharge tube adapter was machined from 9/16 in. brass rod stock and threaded for direct insertion into the torch base. A 1/4 in. hole was bored completely through this adapter to allow for the placement of the alumina discharge tube. 


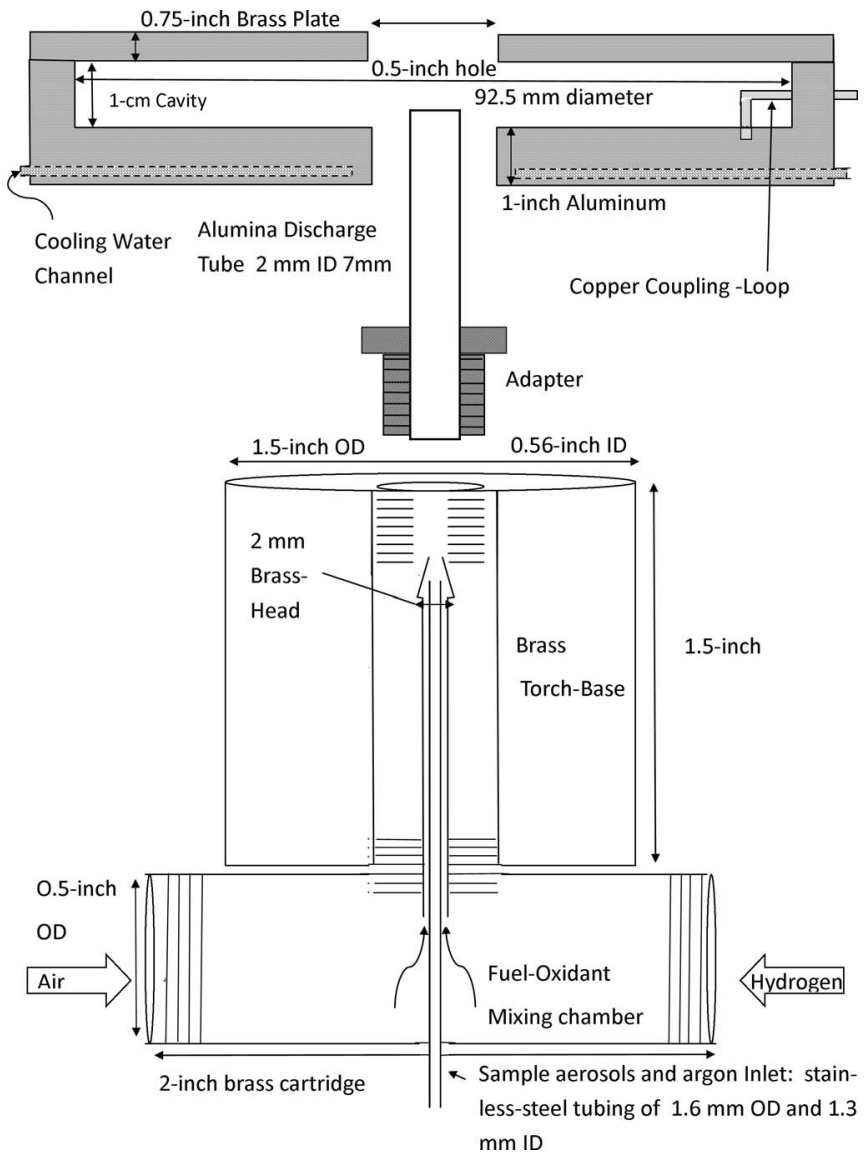

FIG. 1. The microwave induced flame plasma construction and assembly.

\section{B. System layout}

Figure 2 shows the experimental system layout. The 1-cm deep Beenakker aluminum cavity, microwave generator and tuner, and the spectrometer employed were of those published earlier. ${ }^{8}$ Alumina discharge tubes measured $7 \mathrm{~mm}$ outside diameter and $2 \mathrm{~mm}$ inside diameter, were used. A double convex quartz lens (focal length $11.8 \mathrm{~cm}$ and di-

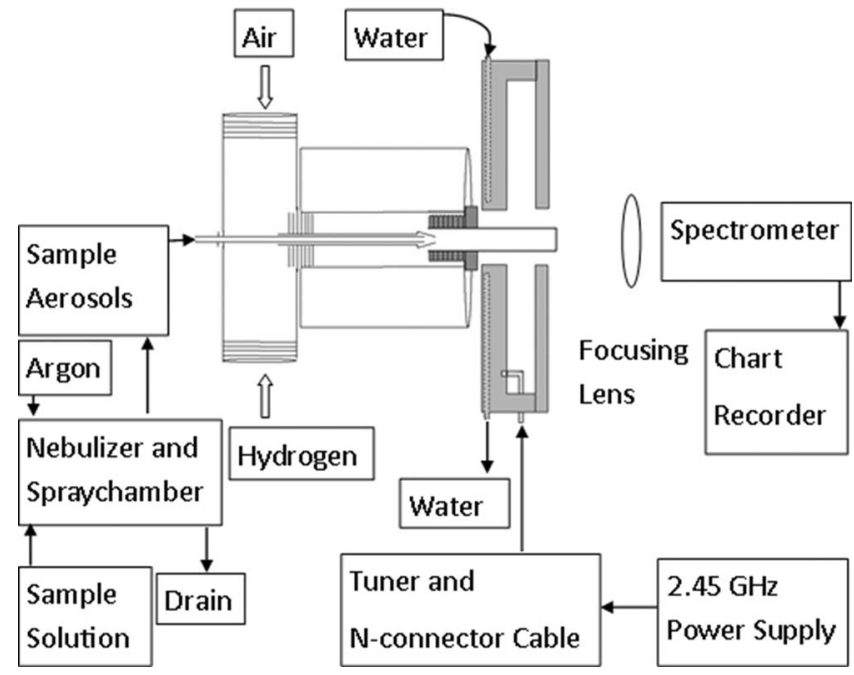

FIG. 2. Equipment layout for the microwave induced flame plasma atomic emission system.
TABLE I. Manufacturer's and instrumental components of the experimental MIFP optical emission system.

\begin{tabular}{|c|c|c|}
\hline $\begin{array}{l}\text { Apparatus or } \\
\text { components }\end{array}$ & Model or description & Manufacturer \\
\hline \multicolumn{3}{|c|}{ MIP system } \\
\hline Microwave generators & MPG-4 357 (1-120 W) & Opthos Instrument, Inc. \\
\hline Triple stub tuner & 1878B & Maury Microwave, Inc. \\
\hline Coaxial cable & RG 214/U $(50 \Omega)$ & $\begin{array}{l}\text { Consolidated Times } \\
\text { Microwave Systems, } \\
\text { Inc. }\end{array}$ \\
\hline Microwave cavities & $\begin{array}{l}\mathrm{TM}_{010} \text { Modified } \\
\text { Beenakker }\end{array}$ & Laboratory Built \\
\hline $\begin{array}{l}\text { Combustion torch and } \\
\text { base }\end{array}$ & & Laboratory Built \\
\hline \multicolumn{3}{|c|}{ Spectrometer } \\
\hline Monochromator & $\begin{array}{l}1870 \text { Focal length; } \\
0.5 \mathrm{~m} \\
\text { F/: } 6.8\end{array}$ & Spex Industries, Inc. \\
\hline Grating & $\begin{array}{l}66 \mathrm{~mm} \times 66 \mathrm{~mm} \\
1200 \text { lines } / \mathrm{mm} \\
300 \text { blaze }\end{array}$ & Bausch and Lomb \\
\hline Stepper motor & Module MSD & Spex Industries, Inc. \\
\hline Computer & 5150 & IBM Corp. \\
\hline PMT & $1911 G$ & Spex Industries, Inc. \\
\hline PMT power supply & 247 & Keithley \\
\hline Amplifier & Current to voltage & Laboratory Built \\
\hline Millivolt meter & $\begin{array}{l}\text { Digital } 112 \mathrm{pH} / \\
\text { millivolt meter } \\
\text { (2 volt maximum) }\end{array}$ & Corning \\
\hline Optic & $\begin{array}{l}\text { Double Convex quartz } \\
\text { lens }\end{array}$ & Unknown \\
\hline & $\begin{array}{l}\text { Focal length } 11.8 \mathrm{~cm} \\
\text { Diameter } 3.7 \mathrm{~cm}\end{array}$ & \\
\hline Chart recorder & 355 & Linear Instruments, Inc. \\
\hline \multicolumn{3}{|c|}{ Sample introduction system } \\
\hline $\begin{array}{l}\text { Concentric glass } \\
\text { nebulizer }\end{array}$ & Concentric flow & $\begin{array}{l}\text { Meinhard and } \\
\text { Associates }\end{array}$ \\
\hline Plasma discharge & $99.98 \% \mathrm{Al}_{2} \mathrm{O}_{3}$ & Coors Porcelain \\
\hline Containment tubes & $\begin{array}{l}7 \mathrm{~mm} \text { outside diameter } \\
2 \mathrm{~mm} \text { inside diameter }\end{array}$ & \\
\hline Support gas & Argon $98.9 \%$ & Liquid Carbonic \\
\hline Combustion gases & $\begin{array}{l}\text { Hydrogen } 98.9 \% \\
\text { Air (breathing quality) }\end{array}$ & Liquid Carbonic \\
\hline Spray chamber & & Sherritt, Godon Mines \\
\hline $\begin{array}{l}\text { Combustion gas flow } \\
\text { meter }\end{array}$ & & Jarrell Ash \\
\hline Support gas flow meter & $0-900 \mathrm{ml} / \mathrm{min}$ & Unknown \\
\hline
\end{tabular}

ameter $3.7 \mathrm{~cm}$ ) was used for collecting the plasma emission onto the monochromator. A Corning digital meter and a strip-chart recorder (Linear Instrument, Inc.) were used for monitoring signal output from the photomultiplier tube. A concentric glass (Meinhard and Associate) nebulizer was used with a glass spray-chamber for sample introduction. Table I summarizes the equipment used.

\section{Materials}

Reagent grade chemicals were used. Metal nitrates were used for preparing aqueous solutions. Lithium acetate 
TABLE II. Instrumental settings and operation parameters using the microwave induced flame plasma.

\begin{tabular}{ll}
\hline \hline Microwave frequency and power & $\begin{array}{c}2.45 \mathrm{GHz} \text { at } 90 \mathrm{~W} \\
\text { (max. value) }\end{array}$ \\
$\begin{array}{l}\text { Plasma viewing mode } \\
\text { Entrance and exit spectrometer slit widths }\end{array}$ & $\begin{array}{l}10 \mu \mathrm{m} \text { except for } \\
\text { chromium } 15 \mu \mathrm{m}\end{array}$ \\
PMT bias & $800 \mathrm{~V}$ \\
TM$_{010}$ resonator cavity dimensions & $1 \mathrm{~cm}$ \\
Depth & $92.5 \mathrm{~mm}$ \\
Diameter & \\
Concentric glass nebulizer & $20 \mathrm{psi}$ argon \\
Pressure & $\sim 400 \mathrm{ml} / \mathrm{min}$ \\
Flow rate & $\sim 1 \mathrm{ml} / \mathrm{min}$ \\
Sample uptake rate & \\
Combustion gases & \\
Hydrogen & $10 \mathrm{psi}$ \\
Pressure & $\sim 120 \mathrm{ml} / \mathrm{min}$ \\
Flow rate aqueous solvent & $\sim 100 \mathrm{ml} / \mathrm{min}$ \\
Flow rate organic solvent & \\
Air & $20 \mathrm{psi}$ \\
Pressure & $\sim 100 \mathrm{ml} / \mathrm{min}$ \\
Flow rate aqueous solvent & $\sim 130 \mathrm{ml} / \mathrm{min}$ \\
Flow rate organic solvent & \\
\hline \hline
\end{tabular}

dihydrate, chromium acetylacetonate, and strontium acetate were used for non-aqueous solutions.

\section{Operation procedure}

A pure argon plasma was first ignited (with a Tesla coil) with a forward power of $60 \mathrm{~W}$ and a nebulizer argon flow rate of $\sim 500 \mathrm{ml} / \mathrm{min}$ and $\sim 300 \mathrm{ml}$ argon support gas through the mixing chamber. The hydrogen and air were then turned on, and the flow rates were gradually increasing while slowly decreasing the support argon flow rate to zero. During this time, continuous tuning was required to prevent extinguishment of the discharge. After about $30 \mathrm{~s}$, the plasma reached a state of equilibrium. This was noted by a color change from a pink plasma and yellow tail flame to one of a pure yellow flame emanating from the discharge tube. The experimental settings were adjusted to those listed in Table II for operation.

\section{DISCUSSION OF RESULTS}

The MIP was generated by tuning the power applied to the modified Beenakker cavity at a lowest reflected power $(<2 \mathrm{~W})$ while maximizing the forward power. If this procedure was not followed, intense Joule heating of the discharge cavity and coaxial cables could occur, thereby damaging the magnetron. When the MIP was properly tuned, alumina tube lifetime was on the order of $1 \mathrm{~h}$ of continuous operation otherwise discharge tube lifetime was less than $1 \mathrm{~min}$. If the MIP was extinguished, the whole ignition process must be reinitiated usually with the loss of the discharge tube. A $2 \mathrm{~mm}$ inside diameter (ID) alumina torch was chosen to prevent plasma wander and decrease signal noise due to plasma flicker. If the hydrogen flow rate was above $170 \mathrm{ml} / \mathrm{min}$, with an air flow rate of $130 \mathrm{ml} / \mathrm{min}$, discharge tube lifetime was less than $30 \mathrm{~s}$.

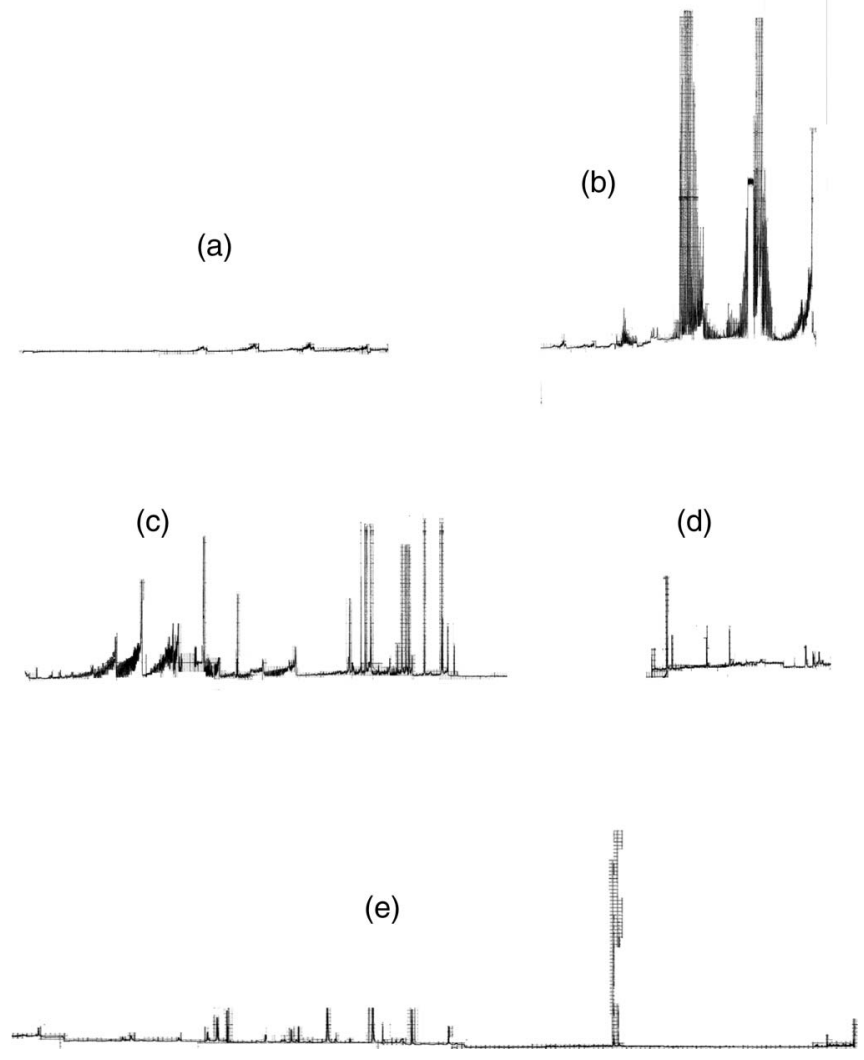

FIG. 3. Background emission regional spectra of the microwave induced flame plasma: (a) $200-280 \mathrm{~nm}$; (b) $280-340 \mathrm{~nm}$; (c) $340-450 \mathrm{~nm}$; (d) 450 $490 \mathrm{~nm}$; (e) 490-700 nm.

During the operation of the MIP, with organic solvent loading (serving as fuel), the flame was allowed to run slightly less hydrogen. It was observed, with organic solvent loading, that if the plasma was allowed to run slightly rich in hydrogen, a green plasma and tail flame occurred. This may be attributed to the green $\mathrm{C}_{2}$ molecular band emission. The intensity of the $\mathrm{C}_{2}$ emission was inversely proportion to the air flow rate. The sample was self-aspirating through the concentric glass nebulizer. Sample blanks were run between each working standard. The signals of the blanks between samples runs were relatively constant throughout the run. Approximately $30 \mathrm{~s}$ between sample and blank runs was required for signal to return to baseline value. There was no plasma instability observed while the sample was aspirated into the MIP. Figure 3 shows the spectral background emission from the microwave induced flame plasma (MIFP).

\section{A. Analytical figures of merit}

A representative atomic emission tracing is shown in Fig. 4. Multiple runs for the elements in the solvents resulted in a signal precision of 5\%-6\% relative standard deviation. Other experimental figures of merit for the MIFP are given in Table III. Excellent linearity $(R>0.997)$ was obtained from the concentrations $(0.5,1,5,10$, and $50 \mathrm{ppm})$ evaluated. The linear dynamic range (signal versus concentrations) was found to cover three orders of magnitude. There is a general decrease in sensitivity for elements run in ethanol ver- 


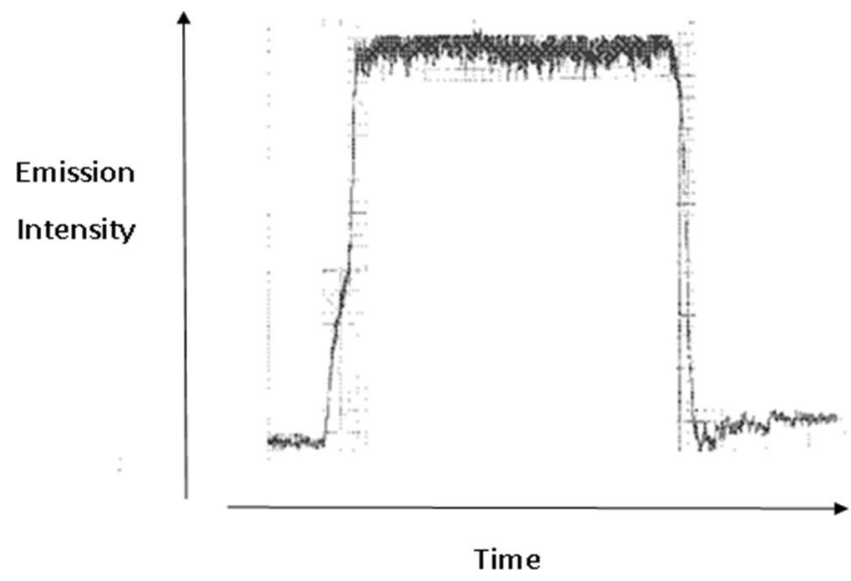

FIG. 4. Typical signal tracing of atomic emission using the microwave induced flame plasma.

sus aqueous solution. $\mathrm{Li}, \mathrm{Sr}$, and $\mathrm{Cr}$ exhibit a $47 \%, 15 \%$, and $1 \%$ reduction, respectively, in sensitivity versus samples run in aqueous solution. There is also a general decrease in sensitivity for elements run in ethanol versus methanol. A reduction of $34 \%, 10 \%$, and $30 \%$, respectively, versus samples run in methanol. The above-mentioned effects may be attributed to the difference in sample viscosity, surface tension between the two solvents, and background emissions. Accompanying the decrease in sensitivity is an augmentation in detection limits (DLs, defined as a corresponding signal equal to three times the standard deviation of the background fluctuation). In general, there is a global decrease in detection limits for elements run in aqueous solution versus samples run in organic solvents. The above described effect may be attributed to differences in physical sample characteristics (e.g., viscosity, surface tension, etc.) and/ or the plasma background when a sample is introduced. For example, the analytical signal for $\mathrm{Cr}$, measured at $425.24 \mathrm{~nm}$, was overlapped by the $\mathrm{OH}$ molecular emission band. The DL for lithium run in both methanol and ethanol, measured at $670.76 \mathrm{~nm}$, is the same. There was no spectral background interference found in this region of the electromagnetic spectrum. Therefore, difference in DL
TABLE IV. Data used to generate the Boltzmann plot and to determine the excitation temperature.

\begin{tabular}{lcccc}
\hline \hline $\begin{array}{l}\text { Ar (I) line } \\
(\AA)\end{array}$ & Intensity & $\begin{array}{l}\text { Energy } \\
\left(\mathrm{cm}^{-1}\right)^{\mathrm{a}, \mathrm{b}}\end{array}$ & $A\left(10^{8} \mathrm{~s}^{-1}\right)^{\mathrm{a}, \mathrm{b}}$ & $g \mathrm{k}^{\mathrm{a}, \mathrm{b}}$ \\
\hline 4200.6 & 21.1 & 116943 & 0.0801 & 7 \\
4198.3 & 13.7 & 117563 & 0.242 & 1 \\
4510.7 & 4.3 & 117563 & 0.102 & 1 \\
5558.5 & 2.6 & 122087 & 0.148 & 5 \\
5572.5 & 1.2 & 123557 & 0.069 & 7 \\
\hline \hline
\end{tabular}

${ }^{\mathrm{a}}$ Reference 9 .

${ }^{\mathrm{b}}$ Reference 10

between aqueous and organic samples must be attributed to physical sample characteristics that affect the droplet diameter. The larger the droplet that is produced by the nebulizer, the more energy is required for de-solvation and the proceeding processes leading to excitation of the analyte.

\section{B. Excitation temperature}

The excitation temperature was determined by two methods. ${ }^{9}$ The first is by way of measuring the slope of the line from a Boltzmann plot and the second is the line pair intensity ratio method (LPIRM). Table IV gives the information used to generate the Boltzmann plot. Table $\mathrm{V}$ gives the information used for the line-pair method. From the Boltzmann plot, a linear least squares line was put through the data and a resultant slope of 0.0019 was obtained. The slope $(m)$ of this line has the following relationship in Eq. (1):

$$
\text { slope }=m=\frac{-0.625}{T_{\mathrm{exc}}},
$$

solving for the excitation temperature $\left(T_{\mathrm{exc}}\right)$ gives a value of $3300 \mathrm{~K}$. The Boltzmann plot showed good linearity with a correlation coefficient of 0.98 . Note that the Einstein coefficients $(A)$ for spontaneous emission are known to about $\pm 10 \%$. The flame temperature of a hydrogen/air chemical flame is on the order of $2000 \mathrm{~K}$, while a pure plasma is on the order of $4000-12000 \mathrm{~K}$. The excitation temperature of

TABLE III. Experimental figures of merit for the microwave induced flame plasma.

\begin{tabular}{|c|c|c|c|c|c|c|c|c|}
\hline Element & $\begin{array}{l}\lambda \\
(\AA)^{\mathrm{a}}\end{array}$ & Solvent ${ }^{\mathrm{b}}$ & $\begin{array}{l}\text { Air/ } \mathrm{H}_{2} \\
(\mathrm{ml} / \mathrm{min})\end{array}$ & $\begin{array}{l}\text { Power } \\
\text { (W) }\end{array}$ & $\begin{array}{l}\text { Sensitivity } \\
(\mathrm{mV} / \mathrm{ppm})\end{array}$ & $\begin{array}{l}\mathrm{DL}^{\mathrm{d}} \\
(\mathrm{ng} / \mathrm{ml})\end{array}$ & $\begin{array}{l}\mathrm{LDR}^{\mathrm{e}} \\
(10 \times)\end{array}$ & $\operatorname{LCC}^{f}$ \\
\hline $\mathrm{Li}$ & 6707.7 & Water & $100 / 120$ & 90 & 34.7 & 15.2 & 3 & 0.999 \\
\hline $\mathrm{Li}$ & 6707.7 & $\mathrm{MeOH}$ & $130 / 100$ & 90 & 27.7 & 24.8 & 3 & 0.999 \\
\hline $\mathrm{Li}$ & 6707.7 & $\mathrm{EtOH}$ & $130 / 100$ & 90 & 18.3 & 24.7 & 3 & 0.997 \\
\hline $\mathrm{Sr}$ & 4607.3 & Water & $100 / 120$ & 90 & 21.8 & 122 & 3 & 0.999 \\
\hline $\mathrm{Sr}$ & 4607.3 & $\mathrm{MeOH}$ & $130 / 100$ & 90 & 16.5 & 481 & 3 & 0.999 \\
\hline $\mathrm{Sr}$ & 4607.3 & $\mathrm{EtOH}$ & $130 / 100$ & 90 & 18.5 & 363 & 3 & 0.997 \\
\hline $\mathrm{Cr}$ & 4252.4 & Water & $100 / 120$ & 90 & 21.5 & 286 & 3 & 0.999 \\
\hline $\mathrm{Cr}$ & 4252.4 & $\mathrm{MeOH}$ & $130 / 100$ & 90 & 30.5 & 260 & 3 & 0.999 \\
\hline $\mathrm{Cr}$ & 4252.4 & $\mathrm{EtOH}$ & $130 / 100$ & 90 & 21.2 & 333 & 3 & 0.999 \\
\hline
\end{tabular}

${ }^{\mathrm{a}} \lambda$ is wavelength in units of angstroms ( $(\AA)$.

${ }^{\mathrm{b}}$ Solvent used $($ methanol $=\mathrm{MeOH}$, ethanol $=\mathrm{EtOH})$.

${ }^{\mathrm{c}}$ Sensitivity in units of millivolts $(\mathrm{mV})$ per part-per-million solution concentration.

${ }^{\mathrm{d}}$ Detection limit (DL) in units of nanograms per milliliter.

${ }^{\mathrm{e}}$ Linear dynamic range (LDR) in powers of ten of solution concentrations.

${ }^{\mathrm{f}}$ Linearity coefficient correlation (LCC). 
TABLE V. Data used to calculate the excitation temperature using line-pairintensity-ratio method.

\begin{tabular}{lcccr}
\hline \hline $\begin{array}{l}\text { Sr (I) line } \\
(\AA)\end{array}$ & Intensity & $\begin{array}{l}\text { Energy } \\
\left(\mathrm{cm}^{-1}\right)^{\mathrm{a}}\end{array}$ & $g^{\mathrm{a}}$ & $A^{\mathrm{a}}$ \\
\hline 4607.3 & 806.45 & 21698 & 0.27 & $0.85 \times 10^{8}$ \\
4962.3 & 113.31 & 35045 & 1.8 & $4.8 \times 10^{8}$ \\
\hline \hline
\end{tabular}

${ }^{\mathrm{a}}$ Reference 11.

the MIP lies between that of a pure hydrogen/air flame and a pure plasma.

The excitation temperature $\left(T_{\text {exc }}\right)$ calculated from the line-pair intensity-ratio method was $3500 \mathrm{~K}$ by using Eq. (2) as follows:

$$
T_{\text {exc }}=\frac{0.625\left(E_{1}-E_{2}\right)}{\log \left(g_{1} A_{1} \lambda_{2} / g_{2} A_{2} \lambda_{1}\right)-\log \left(I_{1} / I_{2}\right)},
$$

where $g$ is the degeneracy, $E$ is the excitation energy, $\lambda$ is the wavelength, and $I$ is the signal intensity. An error of at least $20 \%$ in excitation temperatures, calculated from Boltzmann plot and the line-pair method, must be allowed. ${ }^{11}$ The excitation temperatures obtained in this work agree within $10 \%$ of each other. The excitation temperature serves as a guide to the ability for the atom source to excite electronic transitions.

\section{Degree of ionization and electron density in plasma}

The degree of ionization provides information on the excitation source's ability to atomize and ionize atoms and can be calculated from Eq. (3)

$$
\frac{N^{+}}{N^{o}}=\frac{\left(I \lambda^{3}\right)^{+} u^{+}(g f)^{o}}{\left(I \lambda^{3}\right)^{o} u^{o}(g f)^{+}} \exp \left[\frac{E^{+}-E^{o}}{k T}\right],
$$

where $I$ is the intensity of the spectral line, $N$ is the particle density, $g$ is a statistical weighting factor, $f$ is the Ladenburg's oscillator strength for the emitted line, $\lambda$ is the wavelength, $E$ is the energy of transition, $k$ is the Boltzmann constant, $T$ is the absolute thermodynamic temperature, and $u$ is the partition function. In the equation, the variables associated with the atomic species is denoted with a superscript o and similarly a superscript + denotes variables belonging to the ionic species. Table VI gives the data used to calculate the $N^{+} / N^{\mathrm{o}}$ ratio of 3.3. The energy units given in Table VI are in kiloKaisers (kK), the wavelength is in angstroms, and the absolute thermodynamic temperature in units of Kelvin.
TABLE VI. Data used to calculate the ion density to atom density ratio using the $\mathrm{Sr}(\mathrm{I})$ atomic line centered at 4607.3 angstroms and the $\mathrm{Sr}(\mathrm{II})$ emission centered at $4077.7 \AA$.

\begin{tabular}{lcccccc}
\hline \hline & $I$ & $\lambda$ & $g \mathrm{f}^{\mathrm{a}}$ & $E(\mathrm{kK})^{\mathrm{a}}$ & $T$ & $u^{\mathrm{a}}$ \\
\hline Atom & 697.93 & 4607.3 & 0.27 & 21698 & 3500 & 1.3 \\
Ion & 369.69 & 4077.7 & 0.17 & 24517 & 3500 & 0.17 \\
\hline \hline
\end{tabular}

a Reference 11.

The ion/atom density ratio may be used to obtain the electron density $\left(N_{e}\right)$, via the Saha equation (4), given by

$\log N_{e}=21.245-0.988 V-\log \left(N^{+} / N^{o}\right)-\log \left(u^{+} / u^{o}\right)$,

where $V$ is the ionization potential in volt. In this work, an electron density of $7 \times 10^{14} \mathrm{~cm}^{-3}$ was calculated. This number was calculated by assuming an excitation temperature of $3500 \mathrm{~K}$ and an ionization potential of $5.629 \mathrm{~V}$. A conventional electrical discharge has an electron density on the order of $10^{13}-10^{16} \mathrm{~cm}^{-3}$. The MIP system described in this paper is well within this range.

\section{CONCLUSIONS}

The results of the physical measurements characterize this atom excitation source to be a plasma, with an excitation temperature of $3500 \mathrm{~K}$, an electron number density of $7 \times 10^{14} \mathrm{~cm}^{-3}$, and an ion-to-atom ratio of 3.3. This plasma gives good analytical figures of merit, can tolerate $100 \%$ organic solvent with a solution nebulization rate of $1 \mathrm{ml} / \mathrm{min}$, and therefore, is amenable as a detector for conventional HPLC operations. An improvement in the torch design should reduce the detection limit and prolong the lifetime of the discharge tube.

${ }^{1}$ N. Bings, A. Bogaerts, and J. Broekaert, Anal. Chem. 82, 4653 (2010).

${ }^{2}$ J. Broekaert and V. Siemens, Spectrochim. Acta, Part B 59, 1823 (2004).

${ }^{3}$ R. C. Culp and K. C. Ng, Advances in Atomic Spectroscopy, edited by J. Sneddon (JAI Press, Inc., England, 1995), Vol. 2, p. 215.

${ }^{4}$ K. C. Ng and R. C. Culp, Appl. Spectrosc. 51, 1447 (1997).

${ }^{5}$ J. Giglio and J. A. Caruso, Appl. Spectrosc. 49, 314 (1995).

${ }^{6}$ K. C. Ng and W. L. Shen, Anal. Chem. 58, 2084 (1986).

${ }^{7}$ C. I. M. Beenakker, Spectrochim. Acta, Part B 31, 483 (1976).

${ }^{8}$ K. C. Ng and S. Chen, Microchem. J. 48, 383 (1993).

${ }^{9}$ J. M. Mermet, Chemical Analysis Vol 90, Inductively Coupled Plasma Emission Emission Spectroscopy, Part 2, edited by P. W. I. M. Boumans (Wiley, New York, 1987), p. 353.

${ }^{10}$ B. S. Malone and W. H. Corcoran, J. Quant. Spectrosc. Radiat. Transfer 6, 443 (1966).

${ }^{11}$ S. Greenfield, H. M. McGeachin, and P. B. Smith, Talanta 22, 553 (1975). 